\title{
Editorial 2015 in two voices: past-present-future
}

\author{
Felice Carugati • Aleksandar Baucal
}

Published online: 26 February 2015

(C) Instituto Superior de Psicologia Aplicada, Lisboa, Portugal and Springer Science+Business Media Dordrecht 2015

From the past to the present

The year 2015 marks a turn in the history of the European Journal of Psychology of Education (EJPE): the volume 30 will be published.

During the meeting of the European Foundation of Psychology of Education (EFPE), the Instituto Superior de Psicologia Aplicada (ISPA) and Associate Editors of the EJPE held in Lisbon in May 2014, they have accepted my proposal to finalize my activity as the Editor-inChief that started in 2001 (the EJPE volume 16) with the warm, passionate and invaluable support and collaboration of all the colleagues Associate Editors. Actually, I accepted the role of Editor-in-Chief, during the meeting of the Associate Editors, held in Bologna in April 2000, when the founding Editor-in-Chief, Michel Gilly, had announced his intention to resign after 15 years of dedicated activity since the foundation of EJPE in 1986. He was thanked wholeheartedly for his tremendous work: setting the foundations of the EJPE, building its remarkable diffusion over years and international recognition well beyond Europe.

From 2001 to 2009, the Bologna editorial team held up the everyday activity of governing the reviewing procedure with the help of the Associate Editors, the Editorial Board and a growing number of colleagues from a large number of countries. The publishing activity was guaranteed since the first volume in 1986, by the Instituto Superior de Psicologia Aplicada (ISPA) in Lisbon, thanks to a contract signed between ISPA and the founding Editor, Michel Gilly, on behalf of the first generation of Associate Editors ('The Founding Fathers'): Augusto Palmonari, Frederico Pereira, Anne-Nelly Perret-Clermont, Peter Robinson and Rainer Silbereisen.

During the previous 15 years, the EJPE has made a long-lasting effort to ensure and develop its aims and scope, not only in terms of regularity of the publication but also with a special attention to the quality of the regular papers and the special issues.

The 2010 marks a turning point in the organization of the EJPE because of the agreement signed between the ISPA and Springer Science+Business Media B.V. that allowed the EJPE to benefit from the worldwide organization of Springer and its technical resources and expertise. The Springer support allowed the ISPA and the editorial team to move from an extraordinary

F. Carugati

Alma Mater Studiorum University of Bologna, Bologna, Italy

e-mail: felice.carugati@unibo.it

A. Baucal $(\bowtie)$

University of Belgrade, Belgrade, Serbia

e-mail: abaucal@f.bg.ac.rs 
stage of creative handicraft (the two-times-a-month contacts between Lisbon and Bologna via mail, e-mail, telephone and, more recently, Skype) to 'modern' editorial tools such as the editorial manager system.

Since 2010, 5 years of activity have passed even more rapidly than the previous ten, and together with my colleagues Associate Editors, I decided to pass the editorial activity to a young expert colleague Aleksandar Baucal and his Assistant Editors Jelena Radišić and Nevena Budjevac, to whom I address all my warm and friendly wishes. It is needless to say that they can rely on the support from the Bologna team during the transition period.

In one of the next issues, I will devote a detailed report of the whole activity as the Editorin-Chief in the previous period, in order to maintain and preserve the invaluable scientific and human experience I shared with a tremendous group of colleagues.

\section{From the present to the future: Engaging with diversities to make a point}

It was a great honour for me to be elected as the Editor-in-Chief of the EJPE. The EJPE is one the oldest European journals, established in 1986 by distinguished scholars from Universities of Aix-en-Provence, Bologna, ISPA (Lisbon) and Neuchâtel, and with the exciting idea to promote North-south and East-west collaborations and to create a space for innovative and high quality studies both in theoretical and methodological terms, instead of playing safe with publishing only typical, mainstream papers. I deeply admire the passion and the effort that have been devoted to the EJPE by previous Editors and Associate Editors to pursue such exciting goals in the field of psychology of education. The EJPE is now a wellknown and established journal arriving to the volume 30 that reaches an international audience, rooted in Europe but also open to the international world of researchers interested in the field of psychology of education.

During the preparation period, I have had an important task to create a team of Associate Editors who are outstanding scholar in the field of psychology of education and who share the vision of the EJPE. Therefore, I am pleased to announce new Associate Editors: Guida de Abreu (Oxford Brookes University, UK), Antonio Iannaccone (Université de Neuchâtel, Switzerland), Åsa Mäkitalo (University of Gothenburg, Sweden), Charis Psaltis (University of Cyprus, Cyprus), Francisco Peixoto (ISPA-Instituto Universitário, Portugal), Patrizia Selleri (Alma Mater Studiorum University of Bologna, Italy) and Valérie Tartas (Université ToulouseLe Mirail, France). The new editorial team will be supported by an international Editorial Board drawn from across Europe and representing leading scholars in the field of psychology of education.

I would like to present briefly the leading idea of the new editorial team in order to offer some guidelines for prospective authors. The leading idea can be summarized in the following phrase: 'Engaging with diversities to make a point'.

The first part of the guiding idea 'engaging with diversities...' means that the editorial team is going to look for high-quality papers addressing the relevant psychological aspects of educational processes embedded into different institutional, social, and cultural contexts and focusing on diversities in terms of participants and their educational trajectories (mainstream students as well as students facing different social and cultural difficulties and barriers, teachers in different stages of their career, adults who are engaged in educational processes in different roles and with different goals etc.) and diversities in terms of the socio-cultural context (different kinds of formal educational institutions such as kindergartens, primary and secondary schools, universities as well as diverse processes of informal and non-formal education situated in a specific contexts). Furthermore, we would like to encourage the authors to engage in their studies with variety of theoretical and methodological tools developed in the psychology of education in order to get new insights from studying an object of inquiry from different perspectives and through different lenses by putting them in a productive dialogue. Instead of 
reinforcing the divisions and distancing between different communities of researchers which are based on theoretical and methodological backgrounds, we would like to encourage prospective authors to engage with diverse theoretical and methodological tools in a meaningful way and to search for new knowledge that can emerge from an integrative use of these tools.

The second part of the guiding idea '...to make a point' is supposed to inspire authors to engage deeply in the meaning making process based on findings which resulted from their original research studies or based on the integration of findings from different related studies. It means that authors need to interpret and discuss research results both from the perspective of the research design and methodological tools used as well as from the perspective of relevant theoretical frameworks that represents the grounds for their work. In short, the editorial team encourages the authors to go beyond the mere reporting of own results and towards a reflection of their different meanings and new questions and points of discussion they could imply.

In terms of the typology of the papers that the editorial team is going to be open for the papers reflecting findings from original psychological studies of educational processes as well as the exceptional theoretical and review papers that integrate current knowledge and chart new avenues for future researches will both be welcomed.

Following the assumption that engaging with diversities creates great opportunities for new knowledge, the editorial team wishes to encourage, in particular, the authors from less represented countries and regions as well as young researchers to submit their work to EJPE and to keep going through the review process that can be challenging, but that can also open opportunities for learning and inspiration.

In sum, the new editorial team is looking forward to being a part of the community of researchers that gets together around the EJPE with hope of continuing the great work of our distinguished colleagues and to be able to navigate through upcoming challenges with their sense for a meaningful and innovative engagement.

Felice Carugati. Alma Mater Studiorum University of Bologna, Department of Psychology (retired), viale Berti Pichat, I 40127 Bologna, Italy.

\section{Current themes of research:}

Social interaction and cognitive development. Social representations of development intelligence, and education. IC Technologies and education. Key competencies o digital societies: Beyond international standardized assessment studies

Most relevant publications in the field of Psychology of Education:

Miguel, I., Valentim, J. P., \& Carugati, F. (2010). Intelligence and its development: Social representations and social identities. Papers on Social Representations 19, 23.1-23.33. http://www.psych.lse.ac.uk/psr/

Carugati, F., \& Selleri, P. (2011). Once upon a time ... The case of social representations of intelligence. Papers on Social Representations 20, 33.1-33.15. http://www.psych.lse.ac.uk/psr/

Amaral, V., Peixoto, F., \& Carugati, F. (2011). Representações Sociais da inteligência: estrutura e efeitos de algumas variáveis sociocognitivas. Psicologica 52, 5-18.

Sanches, C., Gouveia-Pereira, M., \& Carugati, F. (2012). Justice judgments, school failure and adolescent deviant behaviour. British Journal of Educational Psychology 82, 606-621.

Selleri P., \& Carugati, F. (2013). Taking care of children and pupils: agreements and disagreements in parents' and teachers' social representations. In G. Marsico, K. Komatsu, A. Iannaccone (Eds.) Crossing boundaries: Intercontestual dynamics between family and school. Charlotte: Information Age Publishing Inc.

Carugati, F., \& Selleri, P. (2014). Social development and the development of social representations: two sides of the same coin? In A. Antonietti, E. Confalonieri, A Marchetti (Eds.) Reflective Thinking in Educational Settings: A Cultural Framework. Cambridge: Cambridge University Press. 
Aleksander Baucal. is a professor at the Department of Psychology at the University of Belgrade. His main field of interest is the socio-cultural developmental and educational psychology and studies of development of new competencies through symmetric (collaborative peer learning) and asymmetric (learning with adults) social interaction. The author's work is also related to improvement of the traditional pre-post test research design by integration with the Item Response Theory (IRT) and involvement of qualitative case studies.

Most relevant publications in the field of Psychology of Education:

Baucal, A., Arcidiacono, F., \& Budjevac, N. (2013). "Is there an equal (amount of) juice?” Exploring the repeated question effect in conservation through conversation. European Journal of Psychology of Education 28(2), $476-495$.

Pavlović Babić, D., \& Baucal, A. (2011). The big improvement in PISA 2009 reading achievements in Serbia: improvement of the quality of education or something else? CEPS Journal 1(3), 31-52.

Tartas, V., Baucal, A., \& Perret-Clermont, A.N. (2010). Can You Think With Me? The social and cognitive conditions and the fruits of learning. In: K. Littleton, C. Howe (Eds.) Educational dialogues: understanding and promoting productive interaction (pp. 64-82). London: Routledge.

Radišić, J., Videnović, M., \& Baucal, A. (2014). Math anxiety - contributing school and individual level factors. European Journal of Psychology of Education. http://link.springer.com/article/10.1007/s10212-014-0224-7

Baucal, A., Pavlović Babić, D., \& Willms, D. (2006). Differential selection into secondary schools in Serbia. Prospects 36(4), 539-546.

Baucal, A. (2006). Development of mathematical and language literacy among Roma students. Psihologija 39(2), 207-227. 